\title{
Effect of mHCN2 gene modification on chronotropic relevant receptors in BMSCs co-cultured with atrial myocytes
}

\author{
CHANDONG DING $^{1 *}$, CUICUI YANG $^{1 *}$, QUANXIA CAO $^{1}$, XIAOXIA ZHU $^{1}$, JIANMING ZHANG $^{1}$, \\ WEN ZHANG ${ }^{1}$, YONGPING WANG ${ }^{2}$ and LONG LI $^{1}$ \\ ${ }^{1}$ Department of Cardiology; ${ }^{2}$ Catheter Intervention Center, The Second Affiliated Hospital of Anhui Medical University, \\ Hefei, Anhui 230601, P.R. China
}

Received July 14, 2016; Accepted April 7, 2017

DOI: $10.3892 /$ etm.2017.4789

\begin{abstract}
Currently, the mechanism of the chronotropic ability of stem cells modified to express the hyperpolarization-activated cyclic nucleotide-gated $(\mathrm{HCN})$ gene remains to be elucidated. The present study assessed the effects of mouse (m)HCN2 gene modification on the expression of chronotropic relevant receptors, adrenergic receptor $\beta 1$ (Adrb1) and cholinergic receptor muscarinic $\mathrm{M} 2$ (Chrm2), in bone marrow stromal cells (BMSCs) co-cultured with atrial myocytes. BMSCs were divided into the following four groups: i) BMSCs transfected with the mHCN2 gene and co-cultured with atrial myocytes for $48 \mathrm{~h}(\mathrm{TF}+\mathrm{CO})$; ii) respective transfection $(\mathrm{TF})$; iii) respective co-culture (CO); and iv) the control group without treatment (CTL). Green fluorescent protein (GFP) was observed in the BMSCs $48 \mathrm{~h}$ after transfection with pEGFP-C1-mHCN2. The expression of Adrb1 and Chrm2 was significantly increased in the $\mathrm{TF}$ and $\mathrm{TF}+\mathrm{CO}$ groups, particularly the $\mathrm{TF}+\mathrm{CO}$ group, compared with the CTL group $(\mathrm{P}<0.05)$. This suggests that BMSCs modified to express the $\mathrm{mHCN} 2$ gene possess autorhythmicity and chronotropic ability, particularly when co-cultured with atrial myocytes. The results of the present study provide novel information regarding the molecular basis of biological pacemakers' chronotropic ability.
\end{abstract}

\section{Introduction}

The rhythm of a heart is determined by the pacemaker cells of the sinoatrial node $(1,2)$. Disease and aging leads to pacemaker cell necrosis and dysfunction, leading to cardiac arrhythmias.

Correspondence to: Professor Chandong Ding, Department of Cardiology, The Second Affiliated Hospital of Anhui Medical University, 678 Furong Road, Hefei, Anhui 230601, P.R. China

E-mail: chandongding@126.com

*Contributed equally

Key words: hyperpolarization-activated cyclic nucleotide-gated, chronotropic ability, stem cells, gene modification, adrenergic receptor $\beta 1$
The prevalence of sinus node dysfunction in the United States has been estimated to be between 403 and 666 per million, with an incidence rate of 63 per million per year requiring pacemaker therapy (3). Electronic pacemaker implantation has become an important method of treatment for cardiac arrhythmias. However, electronic pacemakers are restricted by the electrode implantation sites and the lack of automatic response to neurotransmitters (4). Therefore, an electronic pacemaker is not an ideal therapeutic strategy at present, due to premature pacemaker stimulation, isolated skipped beats, or asynchronous pacing also observed during in vitro and in vivo testing (5). It is expected that more biological pacemakers will developed in the near future.

Currently, there are two ways to build biological pacemakers; autogenous sinus tissue plantation and transgenic technology $(6,7)$. Sinus tissue plantation has been reported to increase the incidence of ventricular arrhythmias $(8,9)$. Embryonic and somatic stem cells are characterized by their ability to differentiate into lineage-specific cell types. Due to ethical controversies, embryonic stem cells are limited in their application (10-13); therefore, somatic stem cell transplantation (14) and the modification of specific genes (15) has become another method of treatment.

Hyperpolarization-activated cyclic nucleotide-gated (HCN) channels, HCN1-4, serve a major role in the automatic rhythm produced by sinus node pacemaker cells $(1,15)$. $\mathrm{HCN} 2$ and HCN4 are primarily located in the sinoatrial node cells (16-19). A number of previous studies have suggested that somatic stem cells transfected with the HCN gene produce a pacemaker current $\left(\mathrm{I}_{\mathrm{f}}\right)(15,20,21)$. However, it remains unclear whether transfected somatic stem cells have chronotropic abilities. As chronotropic responses are closely associated with the activities of sympathetic/parasympathetic nerves (22), sympathetic/parasympathetic receptors, primarily adrenergic receptor $\beta 1$ (Adrb1) and cholinergic receptor muscarinic M2 (Chrm2), are chronotropic relevant receptors. If transfected somatic stem cells have chronotropic abilities, they should express Adrb1, Chrm2 and HCN channel.

In the present study, bone marrow stromal cells (BMSCs), a type of somatic stem cell, were selected in mice as a carrier for mouse (m)HCN2 gene transfection. BMSCs were transfected using a pEGFP-C1-mHCN2 plasmid and induced in an atrial myocyte microenvironment, involved in the cardiomyocyte 
differentiation from mesenchymal stem cells as described previously (23-25), for $48 \mathrm{~h}$. The present study investigated the expression of Adrb1 and Chrm2 mRNA in BMSCs, and then analyzed the effects of mHCN2 gene modification on the expression of Adrb1 and Chrm2.

\section{Materials and methods}

Materials. The pEGFP-C1 plasmid and mHNC2 primers were obtained from Sangon Biotech Co., Ltd. (Shanghai, China). A total of 32 male ICR mice weighing 18-22 $\mathrm{g}$ and aged 4 weeks old were provided by the Experimental Animal Center of Anhui Medical University (Anhui, China). Lipofectamine ${ }^{\mathrm{TM}} 2000$ was purchased from Invitrogen (Thermo Fisher Scientific, Inc., Waltham, MA, USA). Rabbit polyclonal antibodies directed against HCN2 were purchased from ProteinTech Group, Inc. (Chicago, IL, USA). Transwell ${ }^{\circledR}$-COL collagen-coated $0.4 \mu \mathrm{m}$ pore polytetrafluoroethylene (PTFE) membrane inserts were purchased from Corning $\mathrm{GmbH}$ (Wiesbaden, Germany). SYBR Premix Ex Taq (Tli RNase H Plus) was purchased from Takara Bio, Inc. (Otsu, Japan).

Culture of mice BMSCs. The mice provided by the Experimental Animal Center of Anhui Medical University were raised with sterile water and standard food in temperature $20-24^{\circ} \mathrm{C}$, humidity 40-60\% and a 10/14-h light-dark cycle. Mice bone marrow cells were derived from the femora and shinbone of male ICR mice. The present study was performed in accordance with the Guide for the Care and Use of Laboratory Animals of the National Institutes of Health (Bethesda, MD, USA). The animal use protocol was reviewed and approved by the Institutional Animal Care and Use Committee of Anhui Medical University. Following sacrifice, the ends of the femora and shinbone were removed. The marrow of the midshaft was flushed out using $0.1 \mathrm{~mol} / \mathrm{l} \mathrm{PBS}$ with a needle and filtered through a $75-\mu \mathrm{m}$-pore-size cell strainer, then centrifuged at $250 \mathrm{x} \mathrm{g}$ for $5 \mathrm{~min}$ at $20^{\circ} \mathrm{C}$. The supernatant was removed from the tube and the marrow was resuspended in Dulbecco's modified Eagle's medium (DMEM; Gibco; Thermo Fisher Scientific, Inc.) with low glucose. The cell suspension was gently added to $10 \mathrm{ml}$ Percoll separation medium $(1.073 \mathrm{~g} / \mathrm{ml})$ and centrifuged at $450-550 \mathrm{x}$ g for $25-30 \mathrm{~min}$ at $20^{\circ} \mathrm{C}$. The medium was separated into three layers. The middle cell tiers were obtained using a pipette and cultured in DMEM with low glucose supplemented with $10 \%$ fetal bovine serum (FBS; Gibco; Thermo Fisher Scientific, Inc.) at $37^{\circ} \mathrm{C}$ with $5 \% \mathrm{CO}_{2}$. The medium was replaced and non-adherent hematopoietic cells were removed. When the cells reached $70-80 \%$ confluence, the BMSCs were digested with pre-warmed $0.125 \%$ trypsin (Sigma-Aldrich; Merck KGaA, Darmstadt, Germany) for 5-10 $\mathrm{min}$ at room temperature in order to detach cells prior to subculture. The second or third generation, undifferentiated and uniform, was used for the subsequent experiments.

Identification of BMSCs. According to the instruction and operation manual of the flow cytometer (BD FACSCanto II, BD Biosciences, San Jose, CA, USA), flow cytometry (FCM) was used to identify BMSCs in the second generation using fluorescein isothiocyanate (FITC)-conjugated rabbit anti-mouse monoclonal antibodies directed against cluster of differentiation (CD)90, 45 and 34 (1:100; cat. nos. 553004, 553080 and 553733, respectively; BD Biosciences). Cells, seeded at $5.0 \times 10^{5} / \mathrm{ml}$, were assigned to one of three tubes in the microcentrifuge ( $1 \mathrm{ml} /$ tube), centrifuged at $100 \mathrm{x} \mathrm{g}$ for $2 \mathrm{~min}$ at $20^{\circ} \mathrm{C}$, then $900 \mu \mathrm{l}$ of the supernatant was removed. Tube A was treated with anti-CD90 antibodies, tube B with anti-CD45 antibodies, tube $\mathrm{C}$ with anti-CD34 antibodies, and tube D served as negative control and was treated with an immunoglobulin (Ig)G-FITC monoclonal antibody (1:50; cat. no. 553995; BD Biosciences). All tubes were incubated for 25-30 min at room temperature. FCM was then used to examine the amount of CD $90^{+} / \mathrm{CD} 45^{-} / \mathrm{CD} 34^{-}$cells with CytomicsTM FC500 Flow Cytometry CXP software 2003 (Beckman Coulter, Inc., Brea, CA, USA), which is indicative of BMSCs.

Groups. BMSCs were divided into the following four groups: i) BMSCs transfected with the mHCN2 gene and co-cultured with atrial myocytes for $48 \mathrm{~h}(\mathrm{TF}+\mathrm{CO})$; ii) respective transfection $(\mathrm{TF})$; iii) respective co-culture $(\mathrm{CO})$; and iv) control group without treatment (CTL).

Construction of pEGFP-C1-mHCN2. mHCN2 was amplified via the polymerase chain reaction (PCR) using specific primers (Table I). The PCR was performed according to the instructions of Taq PCR MasterMix 2X (Takara Bio, Inc.) including Taq DNA polymerase, dNTPs, $\mathrm{MgCl} 2$ and reaction buffer. The parameters of PCR were denaturing at $95^{\circ} \mathrm{C}$ for $1 \mathrm{~min}$; 30 cycles of $95^{\circ} \mathrm{C}$ for $30 \mathrm{sec}, 62^{\circ} \mathrm{C}$ for $30 \mathrm{sec}$ and $72^{\circ} \mathrm{C}$ for $3 \mathrm{~min}$; followed by an extension of $72^{\circ} \mathrm{C}$ for $5 \mathrm{~min}$. pEGFP-C1 and $\mathrm{mHCN} 2$ were then digested with $\mathrm{SalI}$ and BamHI restriction enzymes at $4^{\circ} \mathrm{C}$ overnight and ligated with DNA ligase at $20^{\circ} \mathrm{C}$ for $1 \mathrm{~h}$. The resulting pEGFP-C1-mHCN2 plasmid was transformed into a DH5 $\alpha$ competent Escherichia coli strain (26). Successfully transformed cells were selected using kanamycin plates, amplified in Luria-Bertani medium at $37^{\circ} \mathrm{C}$ for $12 \mathrm{~h}$ and extracted using a Magen plasmid Endotoxin-free Midi kit according to the instructions (Magen Biotech Co., Ltd., Guangzhou, China). Sequence analysis of the DNA fragment (by Sangon Biotech Co., Ltd., Shanghai, China) and agarose gel electrophoresis (1.5\% gel and ethidium bromide visualization method) were used to confirm whether the mHCN2 fragment was accurately inserted into the pEGFP-C1 plasmid.

Culture of mice atrial myocytes. Using the tissue block enzymolytic method (27), atrial myocytes were isolated from the atriums of 16 male neonatal (1-3 day old) ICR mice provided by the Experimental Animal Center of Anhui Medical University. An enzyme solution of $0.25 \%$ trypsin and $0.5 \%$ collagenase II was prepared in advance. The tissues were minced finely into 1-2 $\mathrm{mm}^{3}$ sections and then washed twice with PBS. The clear sections were transferred into a $15 \mathrm{ml}$ Falcon tube containing $10 \mathrm{ml}$ enzyme solution, placed lengthways in a $37^{\circ} \mathrm{C}$ water bath and incubated for 5-10 min. The digested upper tissues were collected into another tube and isopyknic medium (Gibco; Thermo Fisher Scientific, Inc.) was administered to neutralize the enzymes. The solution was then filtered through a $75-\mu \mathrm{m}$-pore size filter unit and placed into a $100 \mathrm{~mm}$ Petri dish to culture at $37^{\circ} \mathrm{C}$ for $2 \mathrm{~h}$ in order to clear the mixed fibrocyte. Finally, the upper cell suspension was 
Table I. Polymerase chain reaction primers for $\mathrm{mHCN} 2$.

\begin{tabular}{lccc}
\hline mHCN2 primer & Length, bp & Primer sequence (5'-3') & Product size, bp \\
\hline Forward & 26 & GTCGACATGGATGCGCGCGGGGGCGG & 2604 \\
Reverse & 26 & GGATCCTCACAAGTTGGAAGAGAGGC & \\
\hline
\end{tabular}

mHCN2, mouse hyperpolarization-activated cyclic nucleotide-gated channel 2.

obtained by using a pipette, centrifugation at $250 \mathrm{x}$ g for $3 \mathrm{~min}$ at $20^{\circ} \mathrm{C}$ and removing the supernatant, then the cell density was adjusted to $0.5-1 \times 10^{5}$ cells $/ \mathrm{ml}$ and inoculated into $24 \mathrm{~mm}$ Transwell-COL collagen-coated $0.4 \mu \mathrm{m}$ pore PTFE membrane inserts $(1.5 \mathrm{ml} /$ well). The atrial myocytes were observed to beat rhythmically under an inverted microscope following 2-3 days culture in low-glucose DMEM with 10\% fetal bovine serum (Gibco; Thermo Fisher Scientific, Inc.) at $37^{\circ} \mathrm{C}$.

Transfection of pEGFP-C1-mHCN2 into BMSCs and co-culture with atrial myocytes. BMSCs at a confluency of $70-80 \%$ in a 6-well plate were transfected with the pEGFP-C1-mHCN2 plasmid using Lipofectamine 2000 (Invitrogen; Thermo Fisher Scientific, Inc.). Firstly, BMSCs at a density of $1-2 \times 10^{5} / \mathrm{ml}$ were inoculated into 6 -well plate $(1.5 \mathrm{ml} /$ well) with DMEM with low glucose supplemented with $10 \%$ FBS. The medium was replaced with $1.5 \mathrm{ml} /$ well Opti-minimum essential media (Opti-MEM ${ }^{\mathrm{TM}}$; Gibco; Thermo Fisher Scientific, Inc.) the next day. The pEGFP-C1-mHCN2 plasmid $(3.5 \mu \mathrm{g})$ was mixed into $250 \mu \mathrm{l}$ Opti-minimum essential media, and $10 \mu 1$ Lipofectamine 2000 was mixed with $240 \mu 1$ Opti-MEM medium for $5 \mathrm{~min}$. These two solutions were gently mixed and left to rest at room temperature for $20 \mathrm{~min}$. The mixture was then added to the wells in the plates of $\mathrm{TF}+\mathrm{CO}$ and $\mathrm{TF}$ group, which were incubated at $37^{\circ} \mathrm{C}$. The mixture was replaced with DMEM containing $10 \%$ FBS after 4-6 h. The Transwell insert with atrial myocytes was placed into the wells of the plate for co-culture. A total of $48 \mathrm{~h}$ after transfection with pEGFP-C1-mHCN2, green fluorescent protein (GFP) was observed in the BMSCs of the $\mathrm{TF}+\mathrm{CO}$ and TF groups using fluorescence microscopy.

Analysis of $m H C N 2$ protein expression by western blot analysis. The four groups of BMSCs were washed twice with PBS at $4^{\circ} \mathrm{C}$, then added to 6-well plates with Cell Protein Lysis Buffer for Western (Beyotime Institute of Biotechnology, Shanghai, China). The cell density of each group was $2 \times 10^{6} / \mathrm{ml}$ $(1 \mathrm{ml} /$ well). The plates were put on ice for $30 \mathrm{~min}$, and then cell lysates were collected and centrifuged at $12,000 \mathrm{x}$ g for $30 \mathrm{~min}$ at $4^{\circ} \mathrm{C}$. The proteins $(20 \mu \mathrm{l} /$ lane) were subjected to SDS-PAGE on an $8 \%$ gel and then transferred electrophoretically onto polyvinylidene difluoride (PVDF) membranes at $200 \mathrm{~mA}$ for $2 \mathrm{~h}$ in transfer buffer (192 mmol/l glycine, $25 \mathrm{mmol} / \mathrm{l}$ tris-base and 5\% methanol). The PVDF membranes were blocked with $5 \%$ non-fat milk in $0.05 \%$ tris-buffered saline with Tween-20 (TBST) at room temperature for $2 \mathrm{~h}$. Each sample was then incubated with primary antibodies directed against HCN2 (cat. no. 55245-1-AP) and $\beta$-actin (cat. no. 60008-1-Ig) (dilution, $1: 1,000)$ in $5 \%$ non-fat milk in TBST overnight at $4^{\circ} \mathrm{C}$
(ProteinTech Group, Inc.). After three washes in TBST at $20^{\circ} \mathrm{C}$ for $10 \mathrm{~min}$, the membranes were incubated in horseradish peroxidase-conjugated goat anti-rabbit IgG secondary antibodies (dilution, 1:10,000) in 5\% non-fat milk in TBST at room temperature for $1 \mathrm{~h}$, and washed in TBST a further three times. $\beta$-actin was the loading control. The intensity of protein bands was quantified by densitometry using ImageJ software (version 1.36b; National Institutes of Health) to analyze the expression of $\mathrm{mHCN} 2$ in the experimental groups compared with the control group.

Detection of cardiac troponin I (cTnI) by gold immunochromatographic assay (GICA). A GICA strip that consisted of four sections (a sample pad, a conjugate pad, a nitrocellulose membrane and an absorbent pad) was sequentially assembled using a cTnI Fast Test kit, purchased from Getein Biotech, Inc. (Nanjing, China). The conjugate pad was sprayed with anti-cTnI monoclonal antibody (1:1,000; cat. no. 66376-1-Ig; ProteinTech Group, Inc.) labeled with gold nanoparticles. The nitrocellulose membrane was coated with anti-cTnI antibody on the test line to capture the anti-cTnI receptor, which allowed colloidal gold to form a red line. The control line was coated with rabbit anti-mouse IgG (1:1,000; cat. no. 10283-1-AP; ProteinTech Group, Inc.). The kit was thus modified for highly specific antigen-antibody reaction. Colloidal gold dry-type immune chromatography technology was used to quantitatively examine the expression of cTnI protein in BMSCs. The results were analyzed using Getein1100 Immunofluorescence Quantitative Analyzer (IF 1001; Getein Biotech, Inc., Nanjing, China).

Analysis of mHCN2, Adrb1 and Chrm 2 mRNA expression by reverse transcription-quantitative PCR (RT-qPCR). Total RNA was isolated from the cultured cells using TRIzol reagent (Gibco; Thermo Fisher Scientific, Inc.) according to the manufacturer's protocol, and reverse transcribed to cDNA for the subsequent experiment using PrimeScript ${ }^{\mathrm{TM}} \mathrm{RT}$ reagent kit (Takara Bio, Inc.) (28). The mHCN2, Adrb1, Chrm2 and GAPDH oligonucleotide primers were designed using Home-PubMed-NCBI tools (NCBI/Gene/Primer-BLAST, National Institutes of Health) (Table II). qPCR was performed according to the manufacturer's protocol using SYBR Premix Ex Taq (Tli RNase H Plus). The thermocycling conditions were as follows: $95^{\circ} \mathrm{C}$ for $30 \mathrm{sec} ; 40$ cycles of $95^{\circ} \mathrm{C}$ for $5 \mathrm{sec}$; $60^{\circ} \mathrm{C}$ for $34 \mathrm{sec}$; and $95^{\circ} \mathrm{C}$ for $15 \mathrm{sec}, 60^{\circ} \mathrm{C}$ for $1 \mathrm{~min}$ and $95^{\circ} \mathrm{C}$ for $15 \mathrm{sec}$. The amount of product was measured using the $2^{-\Delta \Delta \mathrm{Cq}}$ method (29) and StepOne ${ }^{\mathrm{TM}}$ software (version 2.3; Thermo Fisher Scientific, Inc.). Target gene expression was calculated relative to GAPDH. The reproducibility of the test was confirmed by running $\geq 3$ samples in each group. 
Table II. Primers for reverse transcription-quantitative polymerase chain reaction analysis for mHCN2, Adrb1 and Chrm2 in BMSCs.

\begin{tabular}{lllc}
\hline Target gene & \multicolumn{1}{c}{ Forward (5'-3') } & \multicolumn{1}{c}{ Reverse (5'-3') } & Product size, bp \\
\hline mHCN2 & TGTCGGATGGCTCCTATTTC & TATTCCTCCAGCACCTCGTT & 133 \\
Adrb1 & TGCGAAACAGACAAATCTGG & GTAGAGGACCCACAGCAGGA & 120 \\
Chrm2 & CACTGGGAGAAGTGGAGGAG & GAGACCTGGGTGTGGAGAAG & 106 \\
GAPDH & GTTGTCTCCTGCGACTTCA & GCCCCTCCTGTTATTATGG & 295 \\
\hline
\end{tabular}

mHCN2, mouse hyperpolarization-activated cyclic nucleotide-gated channel 2; Adrb1, adrenergic receptor $\beta 1$; Chrm2, cholinergic receptor muscarinic M2; BMSCs, bone marrow stromal cells.

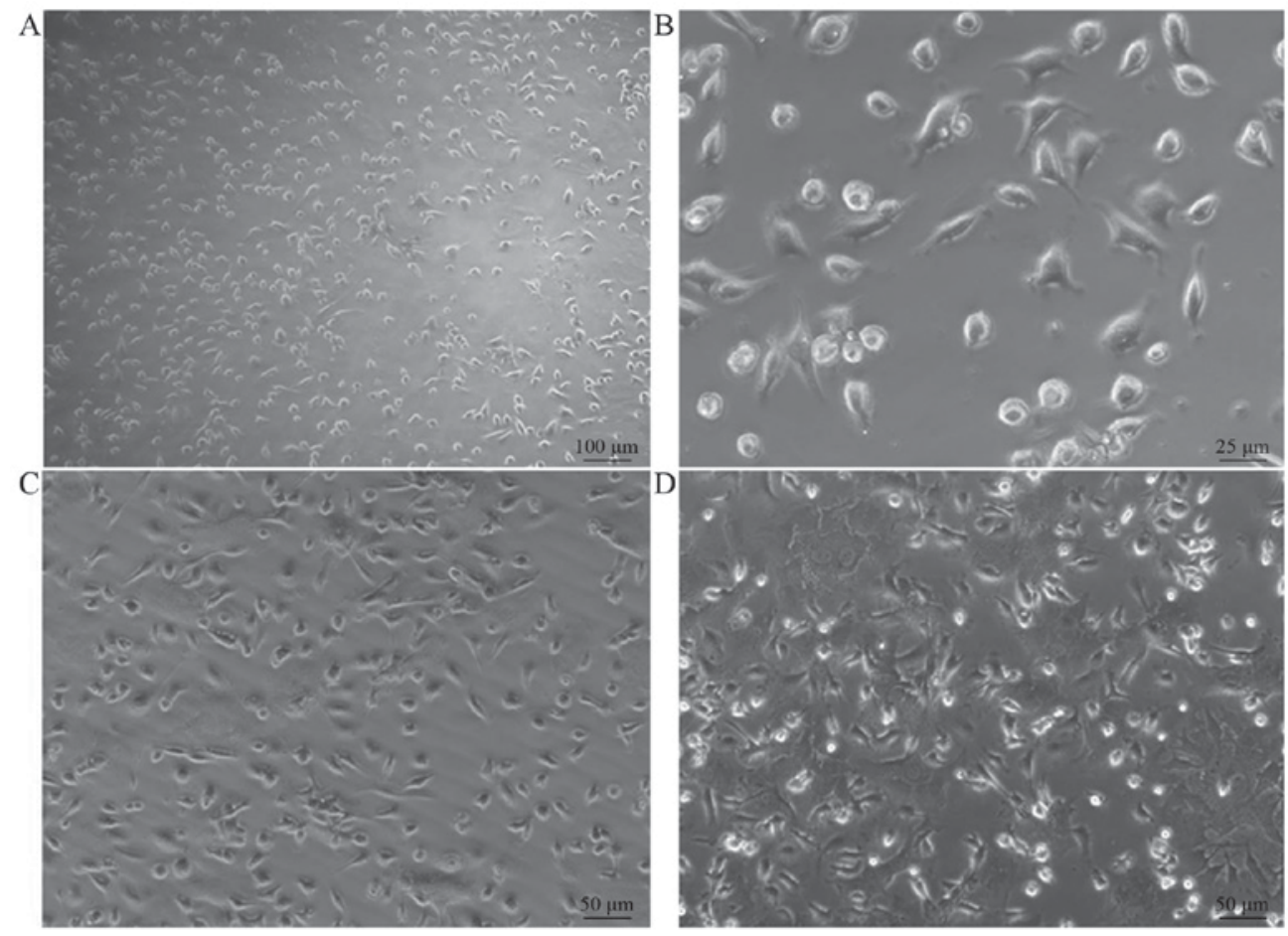

Figure 1. Morphological characteristics of BMSCs. (A) Following $24 \mathrm{~h}$ of culture, a number of cells began to adhere. (B) After $48 \mathrm{~h}$, the adherent cells became fibroblast-like, primarily rhomboid and triangle. (C) After $72 \mathrm{~h}$, the cells appeared to be clustered and looked similar in a clone-growth form. (D) Cells were arranged in swirl when $70-80 \%$ cells were achieved.

Statistical analysis. The data were expressed as the mean \pm standard error of the mean. The statistical significance of differences between groups were performed using one-way analysis of variance followed by a post hoc Fisher's least significant difference test. $\mathrm{P}<0.05$ was considered to indicate a statistically significant difference.

\section{Results}

Morphological characteristics of BMSCs. Freshly transformed BMSCs were round, bright and appeared to be a similar size. Following $24 \mathrm{~h}$ of culture, a number of cells began to adhere (Fig. 1A); $48 \mathrm{~h}$ later, the adherent cells became fibroblast-like, primarily rhomboid and triangle (Fig. 1B); $72 \mathrm{~h}$ later, the cells appeared to be in a clone-growth (clustered and similar) form (Fig. 1C); and the cells were arranged in a swirl when 70-80\% cells were achieved (Fig. 1D). The consistent size, pattern and ability to proliferate were observed even in the third generation.
Specific surface antigen characteristics of BMSCs. BMSCs in all groups were characterized by FCM. It was revealed that the percentage of cells positive for CD90 $(94.1 \pm 1.1 \%)$ was significantly higher compared with that for leukocyte antigen CD45 (3.1 $\pm 1.0 \%)$ and CD34 (2.3 $\pm 1.2 \%)$ (both $\mathrm{P}<0.05$; data not shown). This indicates that the cells extracted from mice bone marrow were uncommitted and multipotent stem cells in the state of undifferentiation.

Morphological characteristics of mice atrial myocyte cells. Atrial myocytes from the atriums of neonatal ICR mice were placed into the upper compartment of the Transwell insert and BMSCs were cultured in the lower compartment (Fig. 2A). The cells were large and oval in shape, with a large nucleus. Following $24 \mathrm{~h}$ of culture, a number of atrial myocytes were adherent (Fig. 2B). Following 72 h of culture, cells spread out and were capable of spontaneous rhythmic beating (Fig. 2C). 

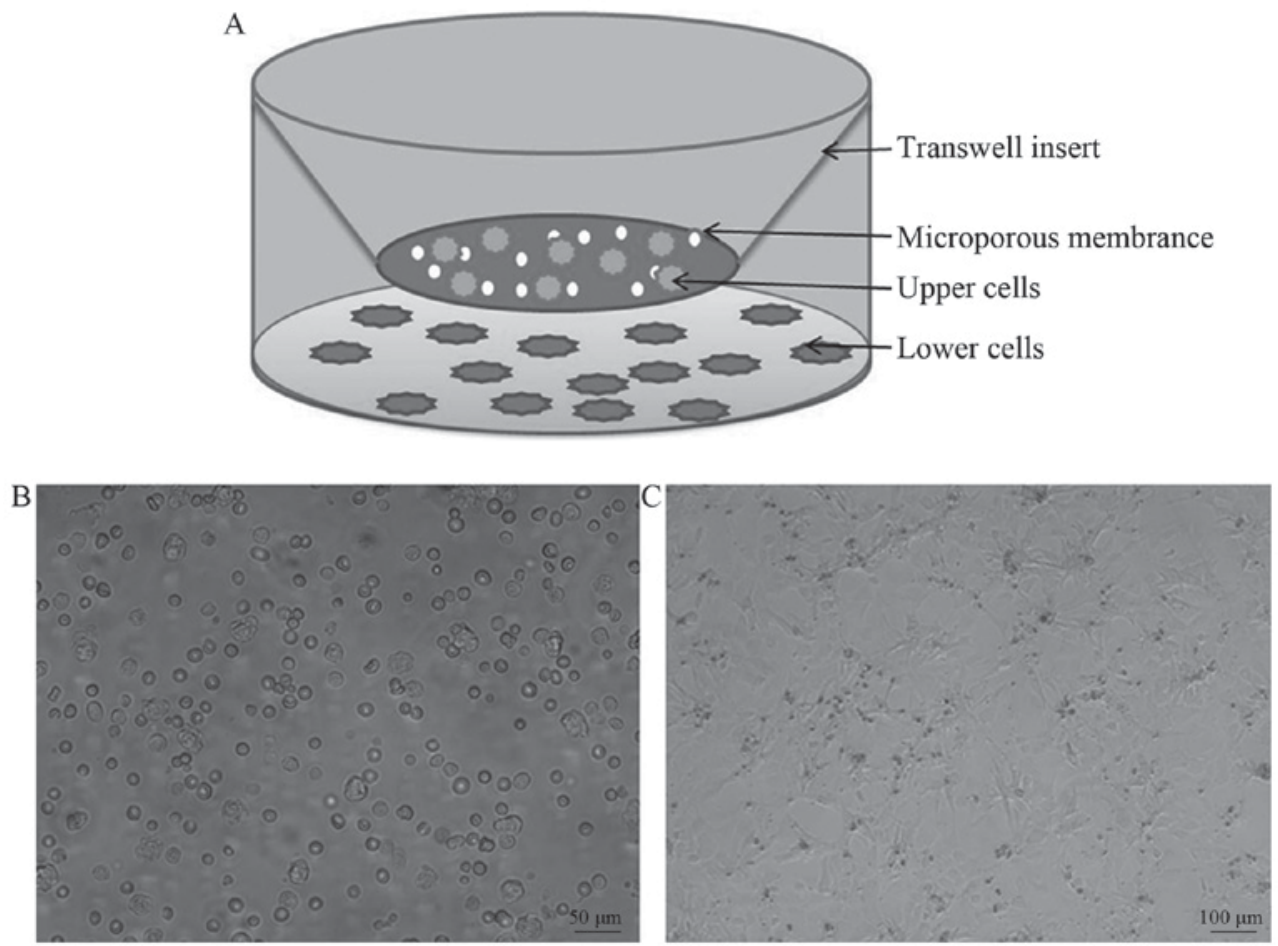

Figure 2. Co-culture of atrial myocytes and BMSCs. (A) Atrial myocytes from the atriums of neonatal ICR mice and BMSCs were cultured in the upper and lower compartment of a Transwell insert, respectively. (B) Atrial myocytes were large and oval in shape, with a large nuclei. (C) Atrial myocytes were capable of spontaneous rhythmic beating. BMSCs, bone marrow stromal cells.

Identification of the $p E G F P-C 1-m H C N 2$ plasmid. The pEGFP-C1-mHCN2 plasmids produced in E. coli were digested and analyzed. DNA fragments of $\mathrm{mHCN} 2(2.6 \mathrm{~Kb})$ and pEGFP-C1 (4.7 Kbp) were identified by agarose gel electrophoresis. The sequence of mHCN2 analyzed by Sangon Biotech Co., Ltd. was identical to the mice gene pool, compared to an NCBI sequence. This confirmed that the mHCN2 fragment was accurately inserted into the pEGFP-C1 plasmid (Fig. 3).

Transfection of pEGFP-C1-mHCN2 into mouse BMSCs. GFP was observed in the BMSCs of the $\mathrm{TF}$ and $\mathrm{TF}+\mathrm{CO}$ groups via fluorescence microscopy, revealing a transfection efficiency of $40-60 \%$ (Fig. 4). This indicates that $50 \%$ of the BMSCs were successfully transfected with pEGFP-C1-mHCN2.

Expression of $m H C N 2$ protein. The results of $\mathrm{mHCN} 2$ protein expression in BMSCs are presented in Fig. 5. The protein bands detected at the expected molecular mass $(\sim 97 \mathrm{kDa})$ indicated that the $\mathrm{HCN} 2$ protein was successfully expressed in the $\mathrm{TF}+\mathrm{CO}, \mathrm{TF}$ and $\mathrm{CO}$ groups (Fig. 5A). The intensity of the $\mathrm{mHCN} 2$ protein bands compared with the $\beta$-actin bands of the $\mathrm{TF}+\mathrm{CO}, \mathrm{TF}$ and $\mathrm{CO}$ groups were significantly 23.2, 22.1 and 4.4 times higher compared with that of the control group, respectively ( $\mathrm{P}<0.05$; Fig. 5B).

Expression of cTnI. The concentration of cTnI in the was assessed using a GICA. Each sample exhibited a control line, and the test line was positive in the $\mathrm{CO}$ and $\mathrm{TF}+\mathrm{CO}$ groups (Fig. 6A). In the CTL and TF groups, only the control line was observed. In the $\mathrm{CO}$ and $\mathrm{TF}+\mathrm{CO}$ groups, the expression of $\mathrm{cTnI}$ was significantly increased to $1.25 \pm 0.29$ and $1.20 \pm 0.07 \mathrm{ng} / \mathrm{ml}$, respectively, compared with that of the CTL group (both $\mathrm{P}<0.05$; Fig. $6 \mathrm{~B}$ ).

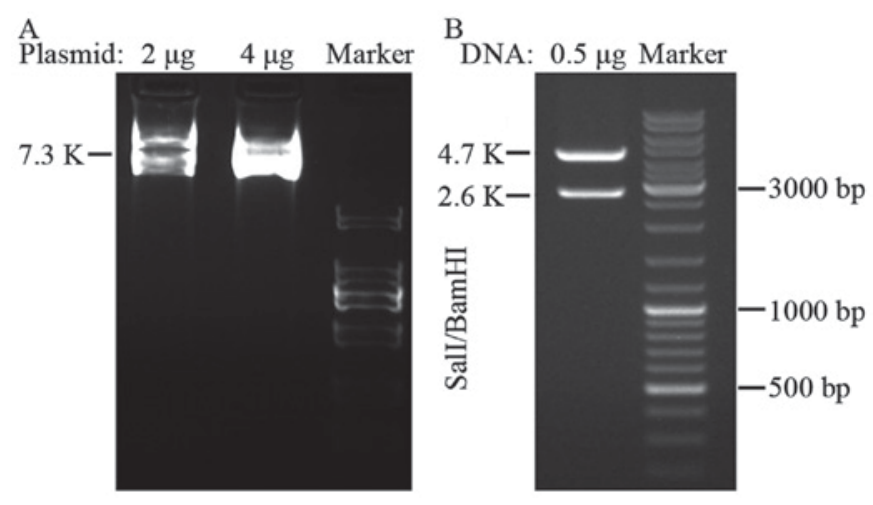

Figure 3. Results of agarose gel electrophoresis. (A) The pEGFP-C1-mHCN2 plasmid presented only one electrophoretic band at $7.3 \mathrm{Kbp}$ by agarose gel electrophoresis. (B) mHCN2 and pEGFP-C1 DNA fragments presented as two electrophoretic bands at 2.6 and $4.7 \mathrm{Kbp}$, respectively. mHCN2, mouse hyperpolarization-activated cyclic nucleotide-gated channel 2 .

mHCN2 transcription. The RT-qPCR analysis of mHCN2 mRNA expression is presented in Fig. 7A. The relative expression of mHCN2 mRNA in the TF + CO and TF groups was $342.52 \pm 67$ and $160.71 \pm 35$, respectively, which was significantly increased compared with the CTL group $(\mathrm{P}<0.05)$. There was very little expression of mHCN2 mRNA in the CO and CTL groups.

Adrb1 and Chrm 2 transcription. The RT-qPCR analysis of Adrb1 and Chrm 2 mRNA expression is presented in Fig. 7B. The relative expression of Adrb1 in the TF + CO and TF groups (52.03 \pm 20 and $34.74 \pm 8.9$, respectively) was significantly increased compared with the CO and CTL groups (both 


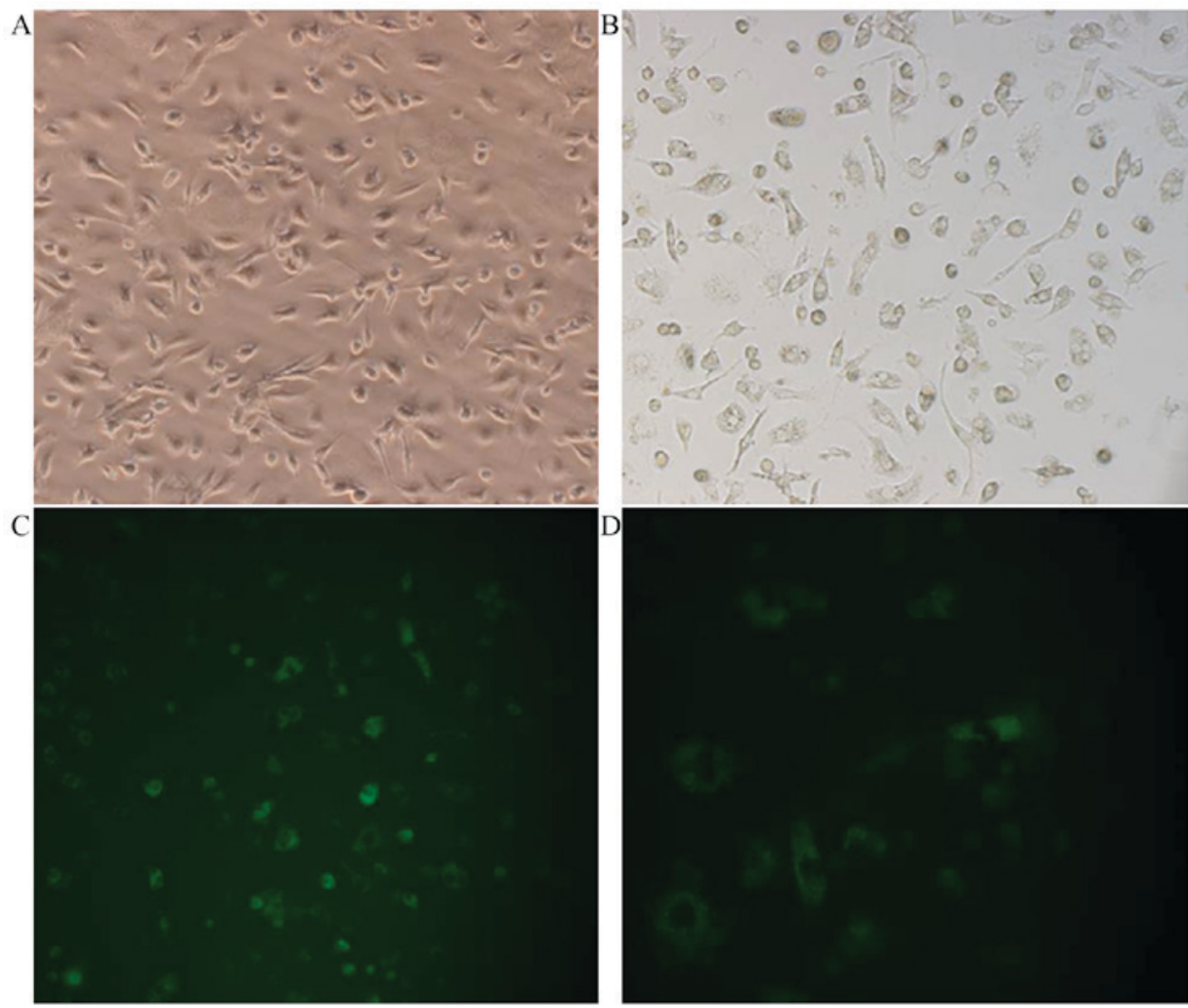

Figure 4. Transfection of pEGFP-C1-mHCN2 into BMSCs. (A) BMSCs prior to transfection at 70-80\% confluence (magnification, x200). (B) BMSCs following transfection with pEGFP-C1-mHCN2 for $48 \mathrm{~h}$ (magnification, x200). BMSCs expressed GFP following transfection with pEGFP-C1-mHCN2 for $48 \mathrm{~h}$, which was revealed by fluorescence microscopy at a magnification of (C) x200 and (D) x400. mHCN2, mouse hyperpolarization-activated cyclic nucleotide-gated channel 2; GFP, green fluorescent protein; BMSCs, bone marrow stromal cells.
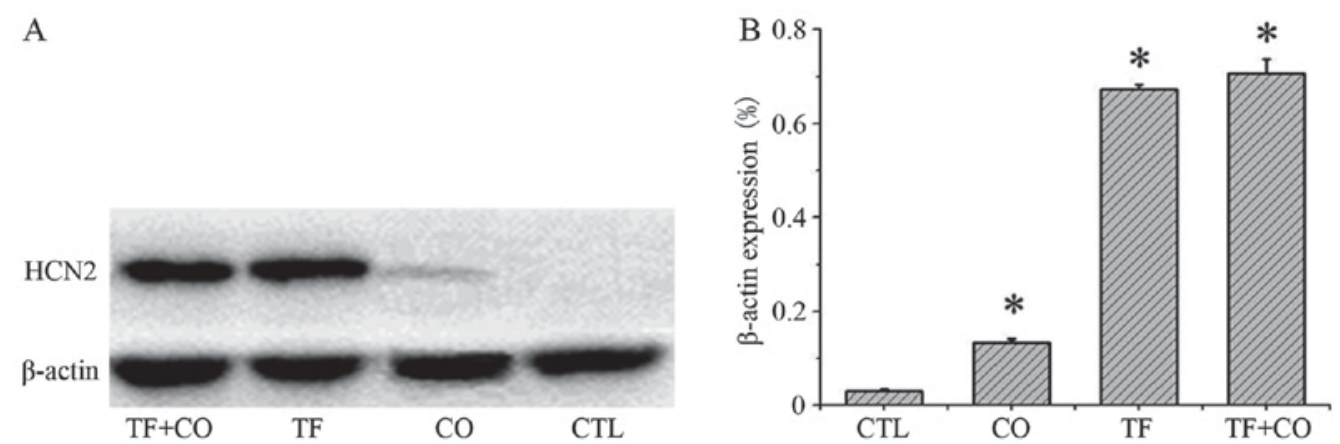

Figure 5. Western blot analysis. (A) Western blot of BMSC expression of mHCN2 protein. Blots obtained using an anti-HCN2 antibody exhibited representative bands at the expected molecular mass of $\sim 97 \mathrm{kDa}$. (B) Quantification of western blot analysis relative to $\beta$-actin demonstrated that the expression of mHCN2 significantly increased in the BMSCs of all three treatment groups. " $\mathrm{P}<0.05$ vs. the CTL group. BMSCs, bone marrow stromal cells; TF, transfection only; $\mathrm{CO}$, co-culture with atrial myocytes; $\mathrm{TF}+\mathrm{CO}$, transfection and co-culture; $\mathrm{CTL}$, control; $\mathrm{mHCN} 2$, mouse hyperpolarization-activated cyclic nucleotide-gated channel 2 .

$\mathrm{P}<0.05)$. The relative expression of Chrm2 was $61.10 \pm 8.8$ and $39.65 \pm 8.3$ in the TF $+\mathrm{CO}$ and TF groups, respectively, which was significantly increased compared with the $\mathrm{CO}$ and CTL groups (both $\mathrm{P}<0.05$ ). There was very little expression of Adrb1 and Chrm 2 mRNA in the CO and CTL group. In addition, Chrm 2 mRNA expression was significantly increased in thee $\mathrm{TF}+\mathrm{CO}$ group compared with the TF group $(\mathrm{P}<0.05)$.

\section{Discussion}

Due to the limitations of electronic pacemakers, a number of biological pacemakers have been established $(30,31)$. It has been demonstrated that BMSCs transfected with the $\mathrm{HCN}$ gene are able to produce a pacemaker current, $\mathrm{I}_{\mathrm{f}}(20,21)$. However, whether $\mathrm{I}_{\mathrm{f}}$ in BMSCs transfected with the HCN gene may be regulated by sympathetic/parasympathetic neurotransmitters remains unknown. The present study aimed to investigate whether BMSCs, transfected with the mHCN2 gene and co-cultured with atrial myocytes, were able to express the chronotropic relevant receptors, Adrb1 and Chrm2. In addition, the expression of $\mathrm{mHCN} 2$, Adrb1 and Chrm 2 was evaluated.

The $\mathrm{mHCN} 2$ channel is characterized by the presence of six putative transmembrane domains $\left(\mathrm{S}_{1}-\mathrm{S}_{6}\right)$, and an ion-conducting pore located between the $S_{5}$ and $S_{6}$ segments (32). The C-terminus 

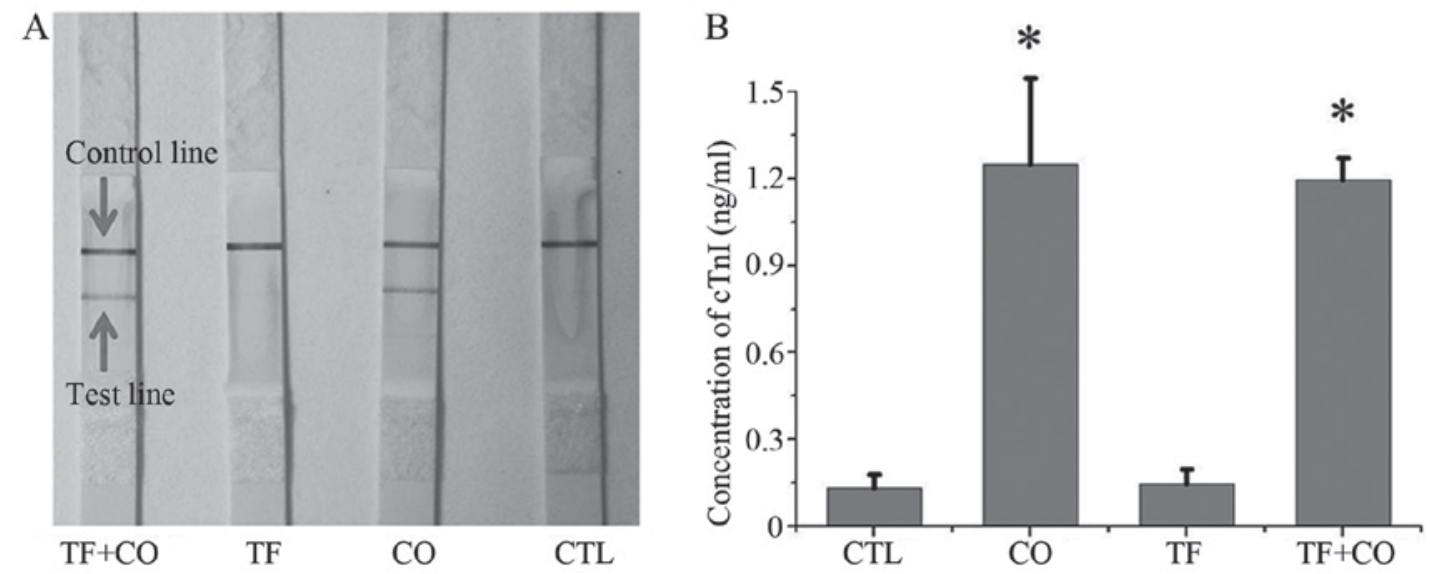

Figure 6. Expression of cTnI in bone marrow stromal cells assessed using a gold immunochromatographic assay. (A) Each sample had one control line, and the test line was observed under the control line in the $\mathrm{CO}$ and $\mathrm{TF}+\mathrm{CO}$ groups. (B) Comparative analysis of cTnI expression; the concentration of cTnI was significantly higher in the $\mathrm{CO}$ and $\mathrm{TF}+\mathrm{CO}$ groups compared with the $\mathrm{CTL}$ group. ${ }^{*} \mathrm{P}<0.05$ vs. the CTL group. Ctn1, cardiac troponin I; TF, transfection only; $\mathrm{CO}$, co-culture with atrial myocytes; TF + CO, transfection and co-culture; CTL, control.
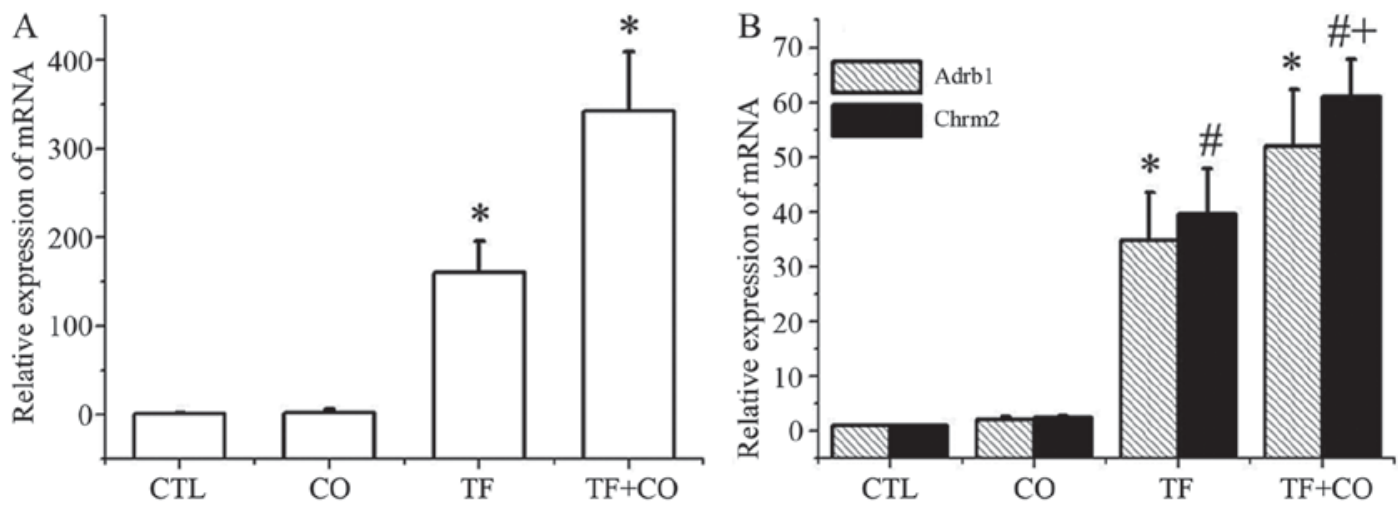

Figure 7. mHCN2, Adrb1 and Chrm 2 mRNA expression. (A) mHCN2 was not expressed in BMSCs of the CO and CTL groups. However, the expression of mHCN2 in the TF and TF + CO groups was significantly increased. (B) The expression of Adrb1 and Chrm2 was nearly undetectable in BMSCs of the CO and CTL groups. The expression of Adrb1 and Chrm 2 was significantly increased in the $\mathrm{TF}+\mathrm{CO}$ and $\mathrm{TF}$ groups. ${ }^{*} \mathrm{P}<0.05$ vs. the $\mathrm{CTL}$ group; ${ }^{\sharp} \mathrm{P}<0.05$ vs. the $\mathrm{CO}$ group; ${ }^{+} \mathrm{P}<0.05$ vs. the TF group. mCHN2, mouse hyperpolarization-activated cyclic nucleotide-gated channel 2; Adrb1, adrenergic receptor $\beta 1$; Chrm2, cholinergic receptor muscarinic M2; BMSCs, bone marrow stromal cells; TF, transfection only; CO, co-culture with atrial myocytes; TF + CO, transfection and co-culture; CTL, control.

of the ion-conducting pore possesses a cyclic nucleotide binding domain (CNBD), which is a binding site for cyclic AMP (cAMP) (32). Pacemaker current is directly activated by intracellular cAMP $(32,33)$, which acts by increasing the probability of an open channel. Sympathetic nervous system stimulation accelerates the cardiac rate by increasing the level of intracellular cAMP, which shifts the voltage-dependence of $\mathrm{I}_{\mathrm{f}}$ activation to a more positive potential $(33,34)$. This mechanism underlies mHCN2 channel/ $\mathrm{I}_{\mathrm{f}}$ modulation by sympathetic ( $\beta$-adrenergic) and parasympathetic (muscarinic) neurotransmitters (35-37). An ideal biological artificial pacemaker cell should have autorhythmicity and chronotropic ability; they should express an adequate amount of $\mathrm{mHCN} 2$ channels and receptors for $\beta$-adrenergic and muscarinic neurotransmitters.

In mammalian heart muscle adrenaline can activate adenylyl cyclase via Adrb1, and an increase in intracellular concentrations of cAMP, which enhances the activities of cyclic nucleotide-gated channels so as to cause positive inotropic cardiac action, chronotropic action and lusitropic action $(38,39)$. BMSCs modified to express the mHCN2 gene express high levels of mHCN2, which may provide additional CNBDs, thus altering levels of intracellularcAMP (30). To meet cellular requirements for cAMP, a high expression of HCN2 provides CNBDs for the cells to accept the regulation of sympathetic nerves and may promote Adrb1 transcription (32). Consistent with this, in the present study BMSCs transfected with pEGFP-C1-mHCN2 were highly expressed mHCN2, Adrb1 and Chrm2 mRNA. Co-culture with atrial myocytes promotes the differentiation of mesenchymal stem cells into cardiomyocytes (40-42) and enhances electrophysiological properties (24). In the present study, the co-culture of BMSCs with the atrial myocytes was able to further increase the expression of mHCN2, Adrb1 and Chrm 2 mRNA. This suggests that BMSCs modified to express the mHCN2 gene possess autorhythmicity and chronotropic ability, particularly when co-cultured with atrial myocytes. The current study therefore provides novel information for future biological pacemaker therapy.

Although the present study indicated that BMSCs transfected with pEGFP-C1-mHCN2 and co-cultured with atrial myocytes were able to express HCN2, Adrb1 and Chrm2, which 
are essential for autorhythmicity and chronotropic ability, the action potentials and ionic currents of the modified cells were not assessed. Therefore, the electrophysiological activities, and response to $\beta$-adrenergic and muscarinic neurotransmitters, of the modified cells requires further investigation.

In conclusion, the present study demonstrated that BMSCs transfected with pEGFP-C1-mHCN2 exhibited increased transcription of Adrb1 and Chrm2. In addition, co-culture with atrial myocytes further increased this transcription. Furthermore, BMSCs co-cultured with atrial myocytes expressed the myocyte-specific marker cTnI. The results of the current study provide a model for future antiarrhythmic gene therapy and novel information regarding the molecular basis of biological pacemakers' chronotropic ability.

\section{Acknowledgements}

The present study was supported by the Anhui Natural Science Foundation of China (grant no. KJ2011Z186). The authors of the current study would like to thank Professor Lin Miao (Central Laboratory of Anhui Medical University, Anhui, China) for her technical assistance, and colleague Miss Yurong Li (School of Public Health, Anhui Medical University, Anhui, China) for statistical analysis support.

\section{References}

1. Stieber J, Hofmann F and Ludwig A: Pacemaker channels and sinus node arrhythmia. Trends Cardiovasc Med 14: 23-28, 2004.

2. Zicha S, Fernández-Velasco M, Lonardo G, L'Heureux N and Nattel S: Sinus node dysfunction and hyperpolarization-activated $(\mathrm{HCN})$ channel subunit remodeling in a canine heart failure model. Cardiovasc Res 66: 472-481, 2005.

3. Mozaffarian D, Benjamin EJ, Go AS, Arnett DK, Blaha MJ, Cushman M, de Ferranti S, Després JP, Fullerton HJ, Howard VJ, et al: Heart disease and stroke statistics-2015 update: A report from the American Heart Association. Circulation 131: e29-e322, 2015.

4. Hauser RG, Hayes DL, Kallinen LM, Cannom DS, Epstein AE, Almquist AK, Song SL, Tyers GF, Vlay SC and Irwin M: Clinical experience with pacemaker pulse generators and transvenous leads: An 8-year prospective multicenter study. Heart Rhythm 4: 154-160, 2007.

5. Harthorne JW: Pacemakers and store security devices. Cardiol Rev 9: 10-17, 2001.

6. Rosen MR, Brink PR, Cohen IS and Robinson RB: Genes, stem cells and biological pacemakers. Cardiovasc Res 64: 12-23, 2004.

7. Zhang H, Yao YL, Duan L, Song ZG, Zou YQ, Zong GJ and $\mathrm{Xu} Z \mathrm{ZY}$ : Autologous sinoatrial node cells heterotopic transplantation for treating bradycardia: An experiment with dogs. Zhonghua Yi Xue Za Zhi 87: 3208-3212, 2007 (In Chinese).

8. Lin G, Cai J, Jiang H, Shen H, Jiang X, Yu Q and Song J: Biological pacemaker created by fetal cardiomyocyte transplantation. J Biomed Sci 12: 513-519, 2005.

9. Cai J, Lin G, Jiang H, Yang B, Jiang X, Yu Q and Song J: Transplanted neonatal cardiomyocytes as a potential biological pacemaker in pigs with complete atrioventricular block. Transplantation 81: 1022-1026, 2006.

10. Gepstein L: Cardiovascular therapeutic aspects of cell therapy and stem cells. Ann N Y Acad Sci 1080: 415-425, 2006.

11. Xue T, Cho HC, Akar FG, Tsang SY, Jones SP, Marbán E, Tomaselli GF and Li RA: Functional integration of electrically active cardiac derivatives from genetically engineered human embryonic stem cells with quiescent recipient ventricular cardiomyocytes: Insights into the development of cell-based pacemakers. Circulation 111: 11-20, 2005.

12. Sartiani L, Bettiol E, Stillitano F, Mugelli A, Cerbai E and Jaconi ME: Developmental changes in cardiomyocytes differentiated from human embryonic stem cells: A molecular and electrophysiological approach. Stem Cells 25: 1136-1144, 2007.
13. Shen Q, Goderie SK, Jin L, Karanth N, Sun Y, Abramova N, Vincent P, Pumiglia K and Temple S: Endothelial cells stimulate self-renewal and expand neurogenesis of neural stem cells. Science 304: 1338-1340, 2004.

14. Jeevanantham V,ButlerM, Saad A,Abdel-Latif A,Zuba-SurmaEK and Dawn B: Adult bone marrow cell therapy improves survival and induces long-term improvement in cardiac parameters: A systematic review and meta-analysis. Circulation 126: 551-568, 2012.

15. Rosen MR, Brink PR, Cohen IS and Robinson RB: Biological pacemakers based on I(f). Med Biol Eng Comput 45: 157-166, 2007.

16. Huang X, Yang $\mathrm{P}$, Yang Z, Zhang $\mathrm{H}$ and Ma A: Age-associated expression of $\mathrm{HCN}$ channel isoforms in rat sinoatrial node. Exp Biol Med (Maywood) 241: 331-339, 2016.

17. Li N, Csepe TA, Hansen BJ, Dobrzynski H, Higgins RS, Kilic A, Mohler PJ, Janssen PM, Rosen MR, Biesiadecki BJ and Fedorov VV: Molecular mapping of sinoatrial node HCN channel expression in the human heart. Circ Arrhythm Electrophysiol 8: 1219-1227, 2015.

18. Stillitano F, Lonardo G, Zicha S, Varro A, Cerbai E, Mugelli A and Nattel S: Molecular basis of funny current (If) in normal and failing human heart. J Mol Cell Cardiol 45: 289-299, 2008.

19. Moosmang S, Stieber J, Zong X, Biel M, Hofmann F and Ludwig A: Cellular expression and functional characterization of four hyperpolarization-activated pacemaker channels in cardiac and neuronal tissues. Eur J Biochem 268: 1646-1652, 2001.

20. Boink GJ, Verkerk AO, van Amersfoorth SC, Tasseron SJ, van der Rijt R, Bakker D, Linnenbank AC, van der Meulen J, de Bakker JM, Seppen J and Tan HL: Engineering physiologically controlled pacemaker cells with lentiviral HCN4 gene transfer. J Gene Med 10: 487-497, 2008

21. Ma J, Zhang C, Huang S, Wang G and Quan X: Use of rats mesenchymal stem cells modified with $\mathrm{mHCN} 2$ gene to create biologic pacemakers. J Huazhong Univ Sci Technolog Med Sci 30: 447-452, 2010.

22. Edelberg JM, Huang DT, Josephson ME and Rosenberg RD: Molecular enhancement of porcine cardiac chronotropy. Heart 86: 559-562, 2001.

23. Xu M, Wani M, Dai YS, Wang J, Yan M, Ayub A and Ashraf M: Differentiation of bone marrow stromal cells into the cardiac phenotype requires intercellular communication with myocytes. Circulation 110: 2658-2665, 2004.

24. Li X, Yu X, Lin Q, Deng C, Shan Z, Yang M and Lin S: Bone marrow mesenchymal stem cells differentiate into functional cardiac phenotypes by cardiac microenvironment. J Mol Cell Cardiol 42: 295-303, 2007.

25. Lu DF, Yao Y, Su ZZ, Zeng ZH, Xing XW, He ZY and Zhang C: Downregulation of HDAC1 is involved in the cardiomyocyte differentiation from mesenchymal stem cells in a myocardial microenvironment. PLoS One 9: e93222, 2014.

26. Xu C, Li ZS, Du YQ, Tu ZX, Gong YF, Jin J, Wu HY and Xu GM: Construction of a recombinant attenuated Salmonella typhimurium DNA vaccine carrying Helicobacter pylori hpaA. World J Gastroenterol 11: 114-117, 2005.

27. Zhou YY, Wang SQ, Zhu WZ, Chruscinski A, Kobilka BK, Ziman B, Wang S, Lakatta EG, Cheng H and Xiao RP: Culture and adenoviral infection of adult mouse cardiac myocytes: Methods for cellular genetic physiology. Am J Physiol Heart Circ Physiol 279: H429-H436, 2000.

28. Wang J, Yao A, Wang JY, Sung CC, Fink LM, Hardin JW and Hauer-Jensen M: cDNA cloning and sequencing, gene expression and immunolocalization of thrombomodulin in the Sprague-Dawley rat. DNA Res 6: 57-62, 1999.

29. Livak KJ and Schmittgen TD: Analysis of relative gene expression data using real-time quantitative PCR and the 2(-Delta Delta C(T)) method. Methods 25: 402-408, 2001.

30. Barbuti A and Robinson RB: Stem cell-derived nodal-like cardiomyocytes as a novel pharmacologic tool: Insights from sinoatrial node development and function. Pharmacol Rev 67: 368-388, 2015.

31. Rosen MR: Gene therapy and biological pacing. N Engl J Med 371: 1158-1159, 2014.

32. Männikkö R, Elinder F and Larsson HP: Voltage-sensing mechanism is conserved among ion channels gated by opposite voltages. Nature 419: 837-841, 2002.

33. DiFrancesco D and Tortora P: Direct activation of cardiac pacemaker channels by intracellular cyclic AMP. Nature 351: 145-147, 1991. 
34. Bois P, Renaudon B, Baruscotti M, Lenfant $\mathrm{J}$ and DiFrancesco D: Activation of $\mathrm{f}$-channels by cAMP analogues in macropatches from rabbit sino-atrial node myocytes. J Physiol 501: 565-571, 1997.

35. Brown HF, DiFrancesco D and Noble SJ: How does adrenaline accelerate the heart? Nature 280: 235-236, 1979.

36. Sebastian S, Ang R, Abramowitz J, Weinstein LS, Chen M, Ludwig A, Birnbaumer L and Tinker A: The in vivo regulation of heart rate in the murine sinoatrial node by stimulatory and inhibitory heterotrimeric G proteins. Am J Physiol Regul Integr Comp Physiol 305: R435-R442, 2013.

37. Abramochkin DV, Kuzmin VS, Sukhova GS andRosenshtraukhLV: Modulation of rabbit sinoatrial node activation sequence by acetylcholine and isoproterenol investigated with optical mapping technique. Acta Physiol (Oxf) 196: 385-394, 2009.

38. DiFrancesco D: Characterization of single pacemaker channels in cardiac sino-atrial node cells. Nature 324: 470-473, 1986.

39. Iakovou K, Kazanis M, Vavayannis A, Bruni G, Romeo MR, Massarelli P, Teramoto S, Fujiki $\mathrm{H}$ and Mori T: Synthesis of oxypropanolamine derivatives of 3,4-dihydro-2H-1,4-benzoxazine, beta-adrenergic affinity, inotropic, chronotropic and coronary vasodilating activities. Eur J Med Chem 34: 903-917, 1999.
40. Badorff C, Brandes RP, Popp R, Rupp S, Urbich C, Aicher A, Fleming I,BusseR,Zeiher AMandDimmeler S: Transdifferentiation of blood-derived human adult endothelial progenitor cells into functionally active cardiomyocytes. Circulation 107: 1024-1032, 2003.

41. Balsam LB, Wagers AJ, Christensen JL, Kofidis T, Weissman IL and Robbins RC: Haematopoietic stem cells adopt mature haematopoietic fates in ischaemic myocardium. Nature 428: 668-673, 2004

42. Makino S, Fukuda K, Miyoshi S, Konishi F, Kodama H, Pan J, Sano M, Takahashi T, Hori S, Abe H, et al: Cardiomyocytes can be generated from marrow stromal cells in vitro. J Clin Invest 103: 697-705, 1999. 